\title{
Experimental Study on the Fractal Features and Permeability Characteristics of Low Metamorphic Coal Pore Structure under Thermal Damage
}

\author{
Zhen Liu, ${ }^{1,2}$ Mingrui Zhang $\mathbb{D}^{1,2}$ Shijian Yu $\mathbb{D}^{1,2}$ Lin Xin, ${ }^{1,2}$ Gang Wang, ${ }^{1,2}$ and Liutao Sun ${ }^{3}$ \\ ${ }^{1}$ College of Safety and Environmental Engineering, Shandong University of Science and Technology, 579 Qianwangang Rd, \\ Huangdao District, Qingdao 266590, China \\ ${ }^{2}$ State Key Laboratory of Mining Disaster Prevention and Control Co-founded by Shandong Province and the Ministry of Science \\ and Technology, Shandong University of Science and Technology, Qingdao 266590, China \\ ${ }^{3}$ School of Management, China University of Mining and Technology, 1 Daxue Rd, Tongshan District, Xuzhou 221116, China
}

Correspondence should be addressed to Mingrui Zhang; zmrsdust@163.com and Shijian Yu; ysj7179@163.com

Received 11 June 2020; Revised 6 August 2020; Accepted 31 August 2020; Published 5 October 2020

Academic Editor: Constantinos Loupasakis

Copyright (C) 2020 Zhen Liu et al. This is an open access article distributed under the Creative Commons Attribution License, which permits unrestricted use, distribution, and reproduction in any medium, provided the original work is properly cited.

\begin{abstract}
Underground coal gasification and exploitation of geothermal mine resources can effectively improve coal conversion and utilization efficiency, and the basic theory of the above technologies generally relies on the change law of the coal pore structure under thermal damage. Therefore, the influence mechanism of the development of the coal pore structure under thermal damage is analyzed by the nuclear magnetic resonance experiment, and the temperature-permeability fractal model is created. The results show that compared with microtransitional pores, the volume of meso-macropores in the coal body is more susceptible to an increase in temperature, which was most obvious at $200-300^{\circ} \mathrm{C}$. During the heating process, the measured fractal dimension based on the $T_{2}$ spectral distribution is between 2 and 3, indicating that the fractal characteristics did not disappear upon a change in external temperature. The temperature has a certain negative correlation with $D_{\mathrm{mNMR}}, D_{\mathrm{MNMR}}$, and $D_{\mathrm{NMR}}$, indicating that the complexity of the pore structure of the coal body decreased gradually with the increase of the temperature. Compared with the permeability calculated based on the theoretical permeability fractal model, the permeability obtained from the temperature-permeability fractal model has a similar increasing trend as the permeability measured by the NMR experiment when the temperature increases. The experimental study on pore structure and permeability characteristics of the low metamorphic coal under thermal damage provides a scientific theory for underground coal gasification and geothermal exploitation.
\end{abstract}

\section{Introduction}

In recent years, there have been many means to achieve coal conversion and comprehensive utilization, including underground coal gasification and geothermal mining [1, 2]. Underground coal gasification is a kind of clean coal comprehensive utilization technology that is converted into combustible gas in situ by a thermochemical reaction $[3,4]$. This technology is one of the important ways to achieve coal conversion, which improves the energy structure, enhances the safety of coal mine production, and considerably improves the resource recovery rate $[5,6]$. Some key points of the tech- nology, such as blasting the coal seam, the movement of airflow, and the movement of the flame working surface, will cause a series of complicated phenomena $[7,8]$, and especially after igniting the coal seam, the combustion will continue to spread. The heat released from the combustion center bakes the coal rock, which causes the mechanical properties of the coal rock and its pore fracture to change, thus affecting the seepage characteristics of the gas in the pore fracture of the coal and determines whether the gasification reaction can continue. Additionally, the geothermal resource is a kind of green renewable energy that is currently being promoted in which deep mine thermal hazards can be 
used as a geothermal resource for resource utilization [9-14]; however, the current geothermal exploration and mining technology are not perfect, especially regarding the basic theory of heat and mass transfer of the coal porous structure, which requires further study. Thus, to steadily control the underground coal gasification process and improve the geothermal exploration and mining technology, it is critical to study the evolution characteristics of the coal structure and permeability characteristics under the heating process. Therefore, this study conducts a series of analyses and studies on the influence mechanism on the development of pore structure and permeability characteristics of the low metamorphic coal under thermal damage.

Coal is the complex porous medium. Recently, a large number of scholars have conducted in-depth studies on the pore structure parameters of coal and rock mass, such as on the pore size, porosity, specific surface area, specific pore volume, and median pore diameter. The research methods have mostly relied on scanning electron microscopy (SEM), mercury intrusion porosimetry (MIP), nitrogen adsorption, nuclear magnetic resonance (NMR), and other methods [15-21]. A series of changes occur in the coal structure under thermal damage. Among them, Li et al. [22] analyzed the changes in the pore structure, moisture, partial volatiles, and organic matter from coal at different heating stages using TG-MS, SEM, $77 \mathrm{KN}_{2}$ adsorption/desorption, and MIP. Liu et al. [23] used a self-developed TRTP-2000 experimental system to carry out high temperature and high-pressure deformation experiments on coal, and combined with various in situ methods, then analyzed and measured the physicochemical evolution characteristics and mechanism of the coal chemical structure. Wang et al. [24] studied the structural transformations in the three coal components, barkinite, vitrinite, and resinite, upon heat treatment from $200^{\circ} \mathrm{C}$ to $700^{\circ} \mathrm{C}$ using high-resolution transmission electron microscopy (HRTEM). Cai et al. [25] used SAXS, $\mathrm{N}_{2}$ adsorption/desorption isotherms, and scanning electron microscopy (SEM) to study the pore structure of Chinese coal under heating and pressure treatment and comprehensively evaluated the pore shape and pore size distribution characteristics of the low rank coal. Natalia [26] studied the development of the porous structure of bituminous coal chars during a certain heating process and found that the development of the porous structure enhanced with the increase in temperature, and then analyzed the reason for this phenomenon and found an enhancement in the evaporation and volatilization. Jolanta [27] used coal petrological methods to determine that the oxidation and thermal change caused by high temperature (above $800^{\circ} \mathrm{C}$ ) in the coal seam fire area will lead to the development of nonstructural cracks and fractures.

In addition to using a series of experimental methods to determine the structure of coal, fractal geometry theory is often used to quantitatively characterize the complex properties of porous media in coal and study the fluid transport properties of the porous media. Recently, Wu et al. [28] used an improved box counting method to calculate the twodimensional and three-dimensional fractal dimensions of CT images of coal samples and confirmed the exponential relationship between porosity and fractal dimension; Liu et al. [29] established the fractal model of permeability via an NMR experiment and fractal geometry theory, then determined the quantitative relationship between the pore structure of a coal sample and permeability in the process of coal seam water injection, and provided an advanced experimental method and theoretical analysis method for the process of coal seam water injection. Additionally, Zhu et al. [30] used $\mathrm{N}_{2}$ adsorption/desorption at $77 \mathrm{~K}$ to analyze the pore structure of coal and calculated the fractal dimension for different pressure ranges by combining the FrenkelHalsey-Hill fractal model; then, the relationship between the fractal dimension and the pore structure was clarified. Shi et al. [31] used X-ray CT and the fractal theory to analyze the physical characteristics of microfractures and the relationship between fractal characteristics and permeability. Peng et al. [32] used low-temperature $\mathrm{N}_{2}$ isotherm adsorption/desorption and the mercury porosimetry experiment to analyze the pore structure of the high rank coal combined with various models to calculate the pore fractal dimension to characterize the heterogeneity of the pore structure. The comprehensive application of the above experimental methods and fractal theory provided the foundation for the analysis of pore structure development under thermal damage conditions in this paper. Therefore, based on these comprehensive, nondestructive, and simple characteristics, for this paper, we choose the self-heating nuclear magnetic resonance equipment to analyze the pore structure change law of coal samples during continuous heating up to $50^{\circ} \mathrm{C}, 100^{\circ} \mathrm{C}$, $200^{\circ} \mathrm{C}$, and $300^{\circ} \mathrm{C}$. Moreover, the fractal dimension of the pore structure is calculated and analyzed by using the fractal theory. Then, a temperature-permeability fractal model is constructed, and the influence mechanism of thermal damage on the pore structure development of a coal body is discussed.

\section{Experiments}

2.1. Samples. Experimental coal samples are taken from the Xiagou Mine (XG) in Bin County, Shaanxi Province, and the Hoxtolgay Fire Area (HS) in Xinjiang Uygur Autonomous region. First, bulky raw coal samples and rock samples obtained in the field are transported to the laboratory for industrial and elemental analyses and then processed into a $\varnothing 25 \times \mathrm{h} 50 \mathrm{~mm}$ cylinder for treatment with increasing temperature using a nuclear magnetic resonance (NMR). The processed coal samples are shown in Figure 1. The results of the industrial and elemental analyses are shown in Table 1 . The results of the initial porosity and permeability for coal samples are shown in Table 2.

2.2. Apparatus and Method. The MINI MR core nuclear magnetic resonance analyzer is used in this experiment, which can achieve the core analysis and imaging function, as shown in Figure 2. The instrument magnet is a permanent magnet, the magnetic field intensity is $0.5 \mathrm{~T}$, the main frequency is $21.3 \mathrm{MHz}$, the probe coil diameter is $60 \mathrm{~mm}$, the minimum echo time is $0.24 \mathrm{~ms}$, the echo time (TE) during the test is $0.2 \mathrm{~ms}$, the waiting time (TW) is $2 \mathrm{~s}$, the echo number is 2000 , the scanning time is 16 , and the experimental 




FiguRE 1: $\emptyset 25 \times$ h $50 \mathrm{~mm}$ coal samples (S represents XG coal samples and D represents HS coal samples).

TABLE 1: Industrial analysis and elemental analysis of the coal samples.

\begin{tabular}{|c|c|c|c|c|c|c|}
\hline \multirow{2}{*}{ Coal type } & \multirow{2}{*}{ Number } & \multicolumn{4}{|c|}{ Industrial analysis } & \multirow{2}{*}{ Ro,max $/ \%$} \\
\hline & & $M_{\mathrm{ad}} \%$ & $A_{\mathrm{ad}} \%$ & $V_{\mathrm{ad}} \%$ & $F_{\mathrm{cad}} \%$ & \\
\hline Noncaking coal & $X G$ & 1.86 & 16.51 & 26.76 & 54.87 & 0.59 \\
\hline Long-flame coal & HS & 8.54 & 15.22 & 35.59 & 40.65 & 0.55 \\
\hline Coal type & Number & \multicolumn{5}{|c|}{ Elemental analysis } \\
\hline Noncaking coal & $\mathrm{XG}$ & 66.81 & 3.67 & 9.32 & 0.58 & 1.23 \\
\hline Long-flame coal & HS & 67.75 & 5.41 & 17.38 & 1.42 & 0.96 \\
\hline
\end{tabular}

$M_{\text {ad }}:$ air-dried moisture; $A_{\text {ad }}:$ air-dried ash; $V_{\text {ad }}:$ air-dried volatile matter; $F_{\text {cad }}$ air-dried fixed carbon; Ro,max: vitrinite reflectance.

TABLE 2: The initial porosity and permeability for coal samples.

\begin{tabular}{lcccc}
\hline Coal samples & XG-1 & XG-2 & HS-1 & HS-2 \\
\hline Porosity/\% & 10.2827 & 10.1198 & 19.7656 & 19.2107 \\
Permeability/mD & 0.7543 & 0.6909 & 10.1325 & 8.7613 \\
\hline
\end{tabular}

environment temperature is $32^{\circ} \mathrm{C}$. The $T_{2}$ relaxation distribution is calculated by using the joint iterative reconstruction technique after the test, and the number of iterations is 10,000 . To satisfy the need for the continuous temperature measurement of experimental samples for the nuclear magnetic resonance analyzer, the equipment is equipped with a temperature control system. The temperature control module of a single chip computer is used to control the experimental temperature, and the temperature setting information given by the nuclear magnetic resonance spectrometer system is accepted. The heating and cooling control are realized by changing the direction of the DC current flowing through the semiconductor refrigerant sheet. Meanwhile, constant temperature circulating water is used to remove the heat generated on the semiconductor connection material to achieve the expected variable temperature conditions. The schematic diagram of the equipment is shown in Figure 2.

In this experiment, firstly, the raw coals collected from the site are processed into cylindrical raw coal standard samples with a diameter of $25 \mathrm{~mm}$ and a height of $50 \mathrm{~mm}$, which accord with the experimental requirements, so as to conduct NMR test of coal structure under heating conditions. Then, two samples from each kind of coal (XG and HS) are heated 


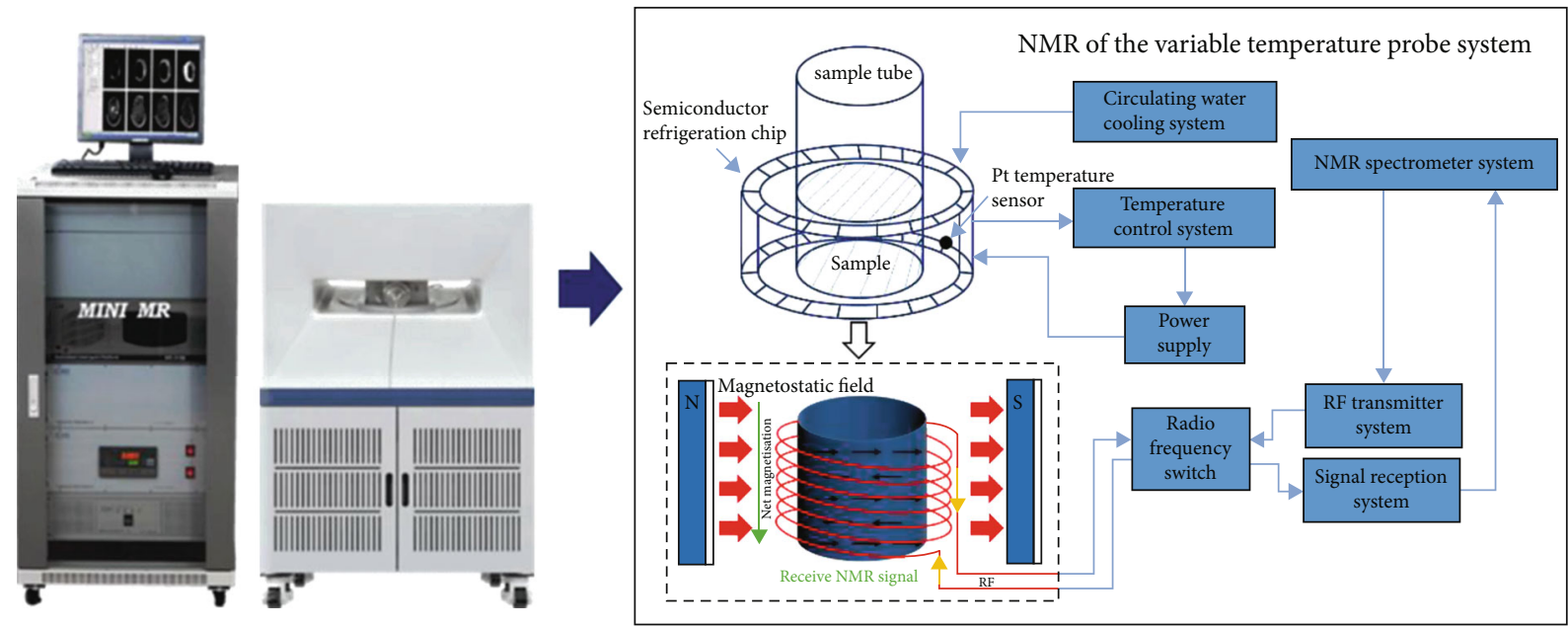

FIGURE 2: MINI MR nuclear magnetic resonance spectrometer.

to $50^{\circ} \mathrm{C}$ for the water saturation test. After the test, the samples are heated to $100^{\circ} \mathrm{C}$ for the same test. Afterwards, the samples are heated to $200^{\circ} \mathrm{C}$ and $300^{\circ} \mathrm{C}$ for the water saturation test until four temperature points are tested. $T_{2}$ spectrums at each temperature are obtained, and the influence mechanism of thermal damage on the development of the pore structure of coal samples is analyzed.

\section{Results and Analyses}

3.1. The Variation of the $T_{2}$ Spectrum Distribution with the Temperature. The magnitude of the $T_{2}$ spectrum amplitude as measured by the NMR experiment reflects the total hydrogen content of a certain diameter pore [33]. Therefore, the variation in water content of coal samples at different temperatures can be represented by the variation in the $T_{2}$ spectrum amplitude. Figure 3 shows the variation of the $T_{2}$ spectrum with the temperature under cyclic heating conditions.

As Figure 3(a) shows, for the XG coal samples, the measured $T_{2}$ spectrum at four temperature points has obvious bimodal characteristics, and the left peak area is larger than the right peak area. Additionally, with an increase in the temperature, the amplitudes of two peaks of the $T_{2}$ spectrum obviously increase, indicating that the amounts of water entering the XG coal samples increase with the increase of the temperature. As Figure 3(b) shows, for the HS coal samples, the measured $T_{2}$ spectrums at $50^{\circ} \mathrm{C}, 100^{\circ} \mathrm{C}$, and $200^{\circ} \mathrm{C}$ have bimodal characteristics, and the measured $T_{2}$ spectrums at $300^{\circ} \mathrm{C}$ have three peaks. With the increase of the temperature, the left peak amplitude of the $T_{2}$ spectrum decreases, and the right peak amplitude of the $T_{2}$ spectrum increases, indicating that the amounts of water entering the smaller pore structure of the HS coal samples decrease with the increase of the temperature, and the amounts of water entering the larger pore structure of the HS coal samples increase with the increase of the temperature.

3.2. The Variation of the Pore Size Distribution with the Temperature. When the core is saturated with the single fluid, the relaxation is mainly determined by the surface relaxation, which is the relaxation of the surface of the coal to the fluid, and is related to the pore specific surface (the ratio of the specific surface area of the pore in the coal to the pore volume), so the $T_{2}$ distribution can more reliably reflect the rock pore size and its distribution, that is, $T_{2}$ is directly proportional to the pore size $[34,35]$. Figure 4 shows the variation of the pore size distribution with the temperature.

$$
\frac{1}{T_{2}}=\rho_{2}\left(\frac{S}{V}\right)_{\text {porosity }}=F_{s} \frac{\rho_{2}}{r}
$$

$T_{2}$ is the relaxation time, and $\rho_{2}$ is the surface relaxation rate of $T_{2}$; it is related to the nature of coal, where a pore is assumed to be a cylinder with radius $r$ (the empirical value of the sample in the calculation is $\left.\rho_{2}=50.00 \mu \mathrm{m} / \mathrm{s}\right), S$ is the pore surface area, $V$ is the pore volume, $(S / V)_{\text {porosity }}$ is the pore specific surface area, and $F_{s}$ is the geometry shape factor.

According to Huoduote's decimal classification system of pore size [36], pores of the tested coal samples cover micropores $(r \leq 10.00 \mathrm{~nm})$, transition pores $(10.00 \mathrm{~nm} \leq r \leq 100.00$ $\mathrm{nm})$, mesopores $(100.00 \mathrm{~nm} \leq r \leq 1000.00 \mathrm{~nm})$, and macropores $(r \geq 1000.00 \mathrm{~nm})$. As shown in Figure 4, the pore structure of the HS coal samples is considerably affected by the temperature compared with the XG coal samples. On the micropore scale, the pore volumes of the HS coal samples decrease with the increase of the temperature, especially at $200-300^{\circ} \mathrm{C}$, whereas that of the XG coal samples hardly change with the increase of the temperature. On the transition pore scale, the pore volumes of the HS coal samples vary slightly in the range of $50-100^{\circ} \mathrm{C}$; in the range of $100-300^{\circ} \mathrm{C}$, the pore volumes decrease significantly with the increase of the temperature, and the pore volumes of the XG coal samples decrease as a whole with an increase of the temperature, although the variation was small. On the mesopore scale, in the range of $50-200^{\circ} \mathrm{C}$, the pore volumes of the $\mathrm{HS}$ and $\mathrm{XG}$ coal samples increase with the increase of the temperature 


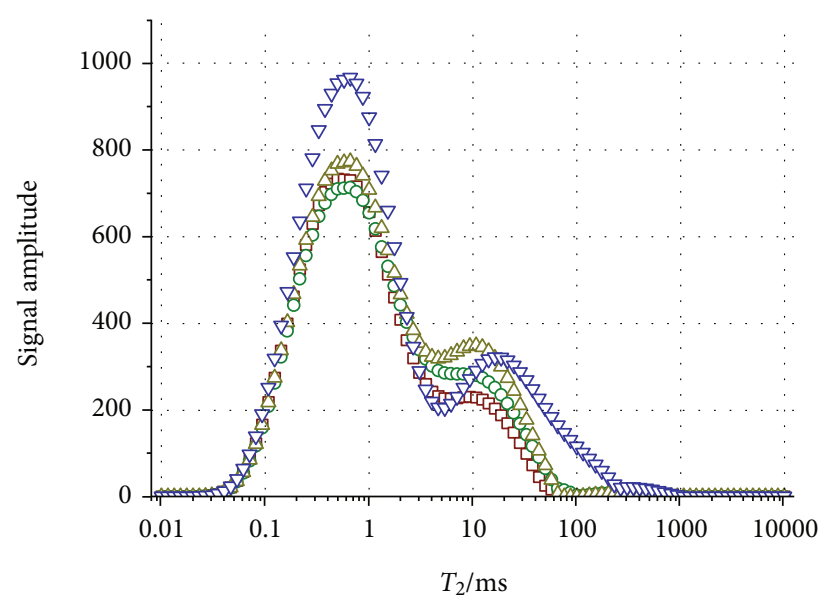

XG-1

口 $50^{\circ} \mathrm{C} \quad \triangle 200^{\circ} \mathrm{C}$

- $100^{\circ} \mathrm{C} \quad \nabla 300^{\circ} \mathrm{C}$

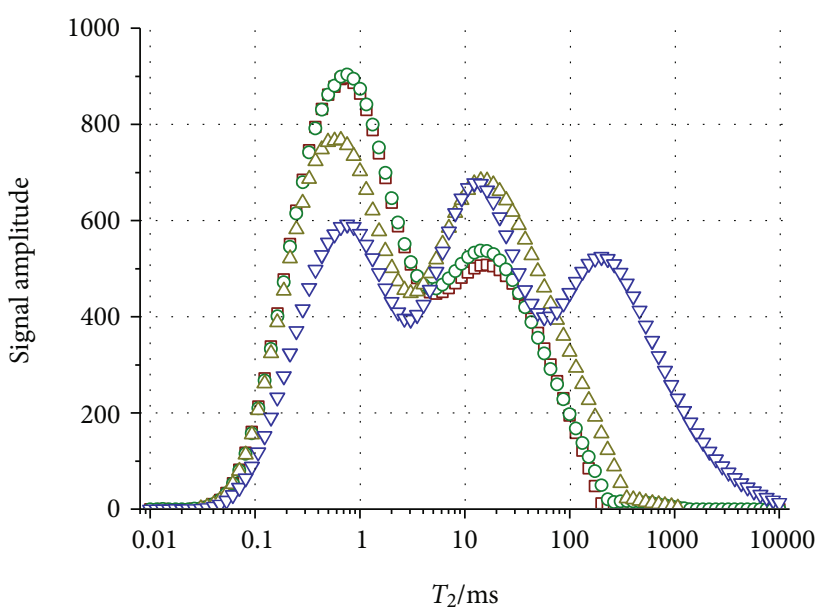

HS-1

口 $50{ }^{\circ} \mathrm{C} \quad \triangle 200^{\circ} \mathrm{C}$

० $100{ }^{\circ} \mathrm{C} \quad \nabla 300{ }^{\circ} \mathrm{C}$



XG-2

व $50{ }^{\circ} \mathrm{C} \quad \triangle 200{ }^{\circ} \mathrm{C}$

○ $100^{\circ} \mathrm{C} \quad \nabla 300^{\circ} \mathrm{C}$

(a)



HS-2

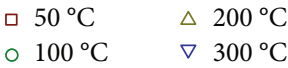

(b)

Figure 3: $T_{2}$ spectral distributions for the experimental samples at different temperatures.

but slowly in the range of $50-100^{\circ} \mathrm{C}$ and sharply in the range of $100-200^{\circ} \mathrm{C}$; they also decrease sharply with the increase of the temperature in the range of $200-300^{\circ} \mathrm{C}$; thus, the pore volumes of the XG coal samples change less than that of the HS coal samples. On the macropore scale, the pore volumes of the XG and HS coal samples remain almost unchanged in the range of $50-100^{\circ} \mathrm{C}$, and within the range of $100-200^{\circ} \mathrm{C}$, the pore volumes of the XG coal samples are almost unchanged; however, the pore volumes of the HS coal samples increase slightly with the increase of the temperature. Additionally, within the range of $200-300^{\circ} \mathrm{C}$, the pore volumes of the XG and HS coal samples increase sharply with the increase of the temperature.

It can be concluded that on the microtransitional pore scales, during the heating process at $50-200^{\circ} \mathrm{C}$, the coal matrix has characteristics of expansion, which results in local stress concentration. When the stress is higher than the strength of the coal sample, the new pores form. The mineral composition around pores is different, and the anisotropy of thermal expansion rate leads to the closure of the original pores; thus, the volume of the microtransitional pores decreases slightly with the increase of the temperature; however, during the process of heating at $200-300^{\circ} \mathrm{C}$, the microtransitional pores interconnect to form the larger pores, resulting in a significant decrease in the volume of the microtransitional pores with the increase of the temperature. On the mesopore scale, during the process of heating at 50$200^{\circ} \mathrm{C}$, the internal pores of the coal samples dehydrate significantly, resulting in a large number of volatile substances. During the process of heating at $200-300^{\circ} \mathrm{C}$, the pyrolysis reaction of the coal body intensifies, and the mesopores penetrate each other and expand into the macropores, which 




XG-1

$\times 50^{\circ} \mathrm{C} \quad * 200^{\circ} \mathrm{C}$

$\ominus 100^{\circ} \mathrm{C} 300^{\circ} \mathrm{C}$

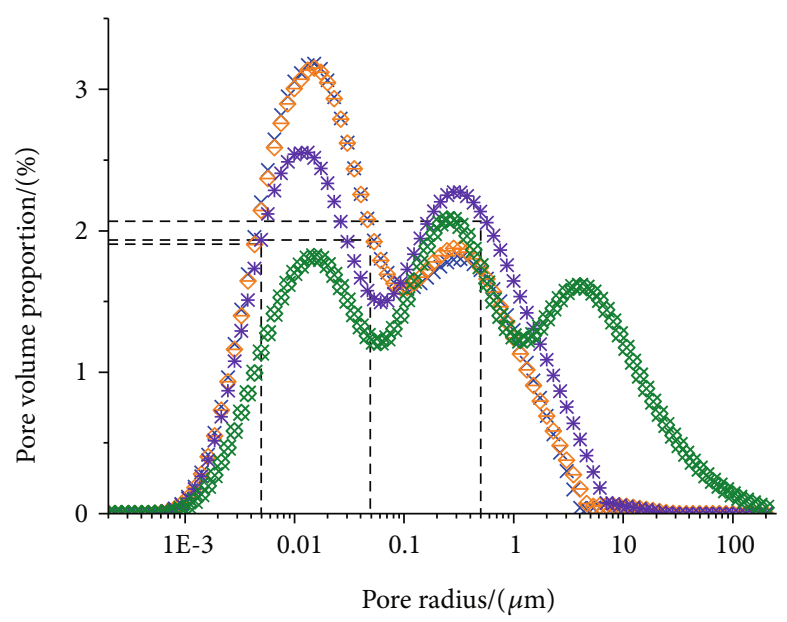

HS- 1

$\times 50{ }^{\circ} \mathrm{C} \quad * 200^{\circ} \mathrm{C}$

$\diamond 100^{\circ} \mathrm{C} 300^{\circ} \mathrm{C}$

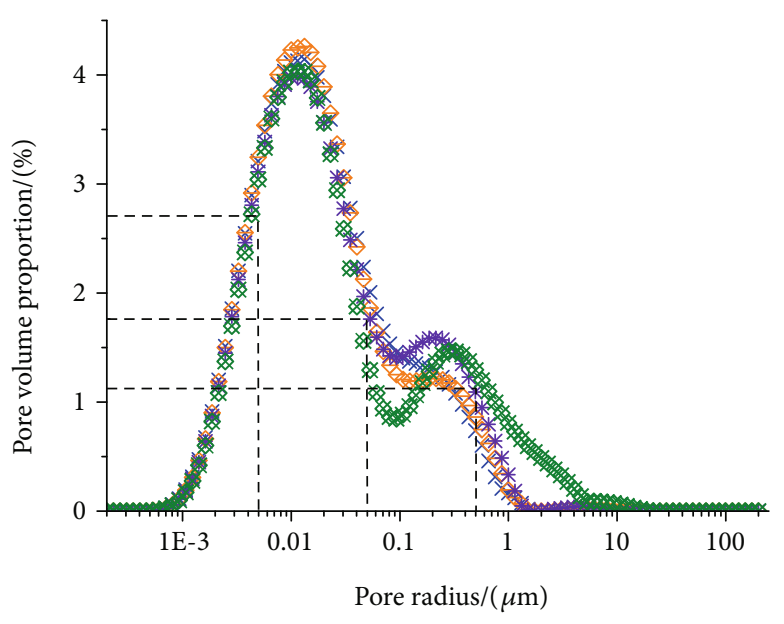

XG-2

$\times 50{ }^{\circ} \mathrm{C} \quad * 200^{\circ} \mathrm{C}$

$\diamond 100{ }^{\circ} \mathrm{C} \not 300{ }^{\circ} \mathrm{C}$

(a)

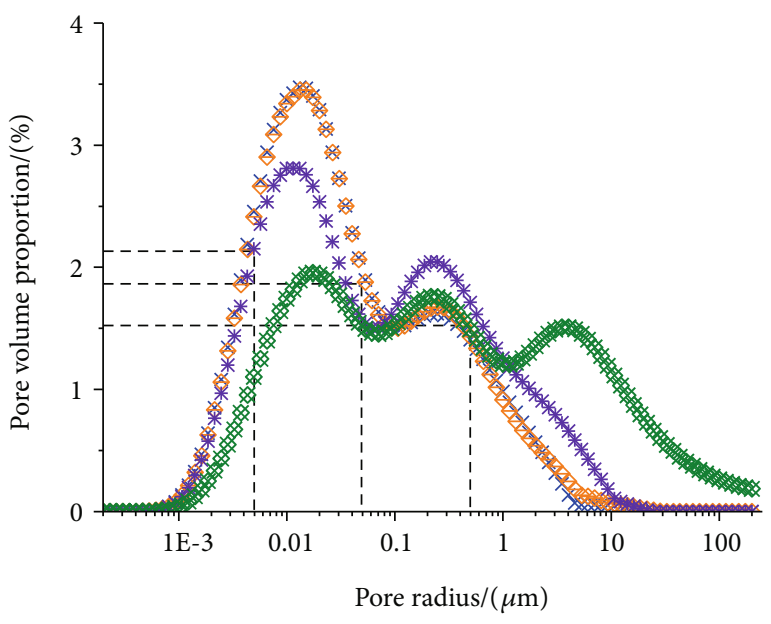

HS-2

$\begin{array}{lll}\times 50{ }^{\circ} \mathrm{C} & * 200^{\circ} \mathrm{C} \\ \diamond & 100^{\circ} \mathrm{C} & 300^{\circ} \mathrm{C}\end{array}$

(b)

FIGURE 4: Pore radius distributions for the experimental samples at different temperatures.

cause the volume of the mesopores in the XG and HS coal samples to increase first and then decrease with the increase of the temperature. On the macropore scale, when the temperature increases to $300^{\circ} \mathrm{C}$, the coal body is torn, and the internal pore structure extends sharply, forming a large number of macropores and even some cracks, which result in a significant increase of the volume of macropores when the temperature approaches $300^{\circ} \mathrm{C}$, especially for the $\mathrm{HS}$ coal samples. Meanwhile, because of the different metamorphic degrees of the XG and HS coal samples, the HS coal samples with higher water and carbon contents and lower metamorphic degrees are more likely to undergo a series of physicochemical reactions under the same heating conditions; thus, the pore structure of the HS coal samples is more affected by temperature than that of the XG coal samples.
3.3. The Variation of the Porosity with the Temperature. The porosity of coal is one of the important indexes used to describe the coal structure [37]. The relationships between the porosity and the temperature of the XG and HS coal samples as determined by NMR are shown in Figure 5 .

As shown in Figure 5, the porosity of the XG and HS coal samples increased with the increase in temperature, and the relationship between the temperature and the porosity satisfied the quadratic equation, as shown in formula (2):

$$
\phi=a T^{2}+b T+c .
$$

$\phi$ is the porosity, $T$ is the temperature, and $a, b$, and $c$ are all constants. 

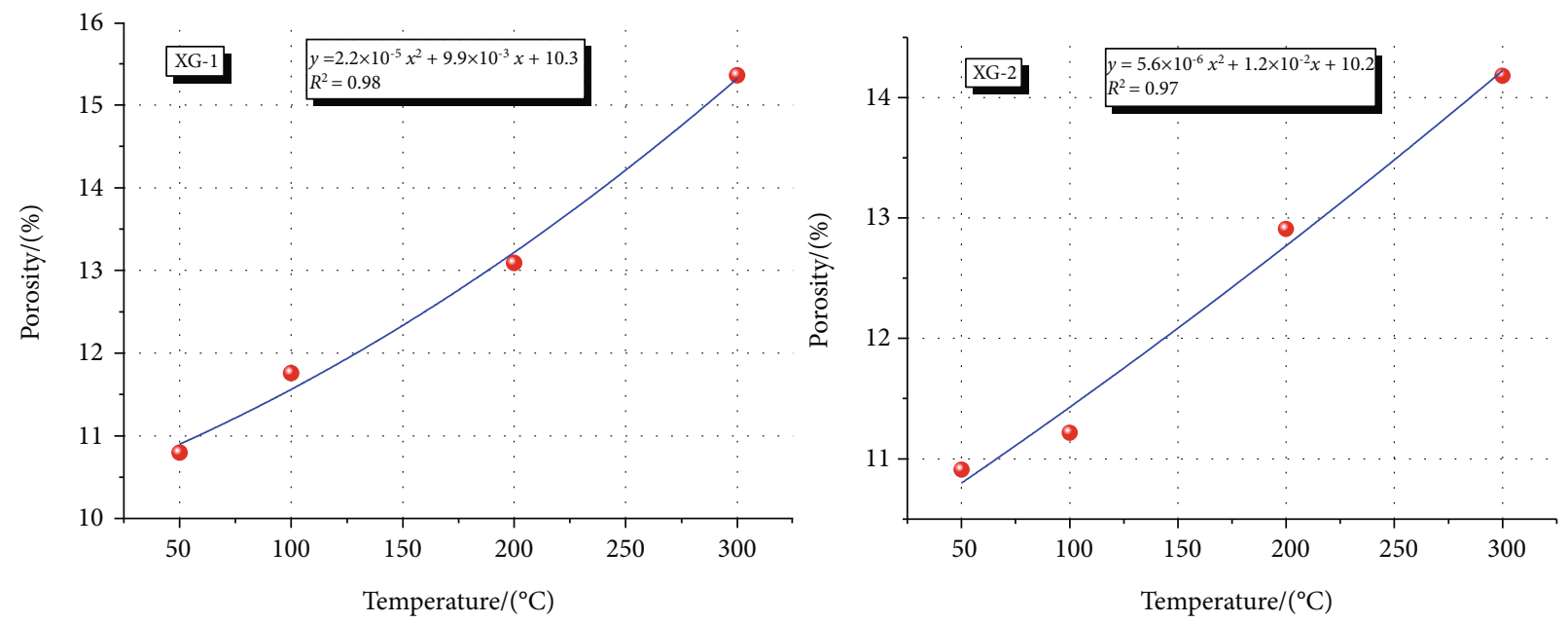

(a)
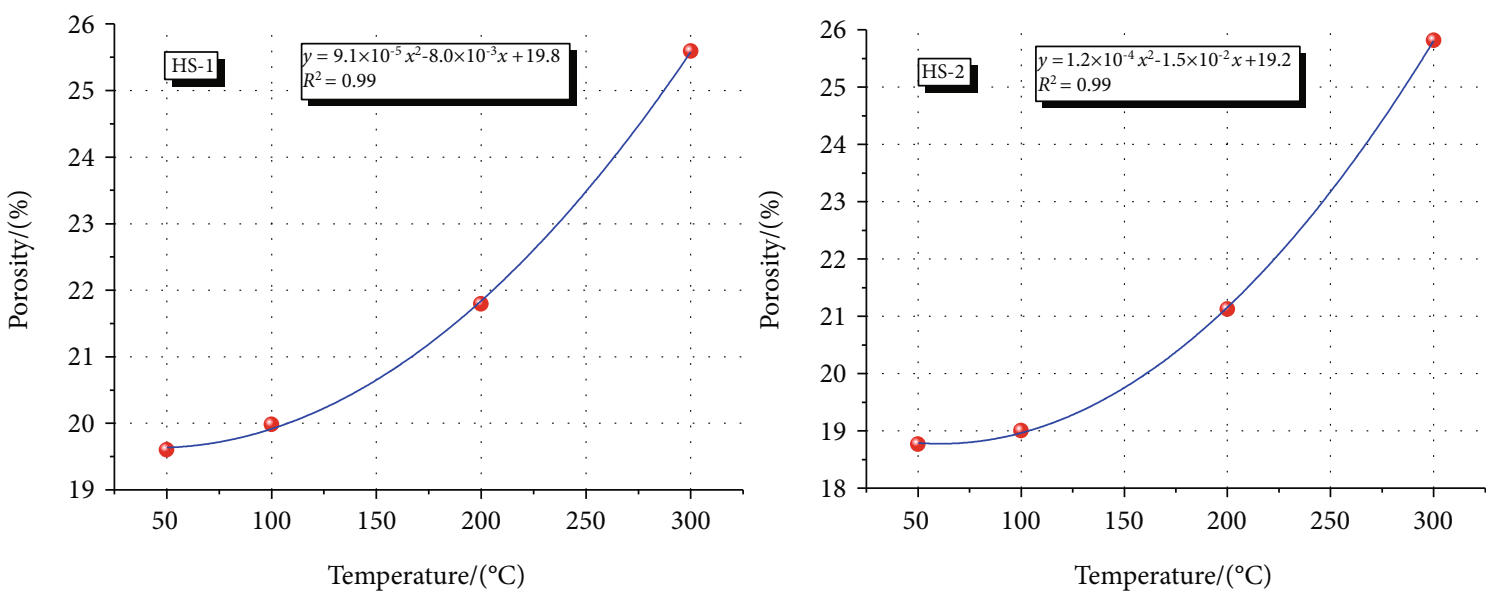

(b)

FIGURE 5: Fitting relationship between the porosity and the temperature of the coal samples.

Figure 5 shows that the porosity of the HS coal varies more with the temperature than that of the XG coal. For the three heating processes of $50-100^{\circ} \mathrm{C}, 100-200^{\circ} \mathrm{C}$, and $200-300^{\circ} \mathrm{C}$, the porosities of the XG and HS coals increase with the temperature. The results show that the degree of thermal damage of the coal sample is low during the heating process at $50-100^{\circ} \mathrm{C}$. Free water in the coal mass escapes outward in the form of vapor, and organic light components volatilize by heat. Meanwhile, the thermal expansion effect of the coal matrix will lead to a change in shape or even closure of some pores, resulting in a small increase in the porosity of the coal. During the heating process at $100-200^{\circ} \mathrm{C}$, the pores develop rapidly and extend gradually, and the pore expansion of the coal body shows a diversified trend, which result in a further increase in the porosity of the coal. During the heating process at $200-300^{\circ} \mathrm{C}$, the coal body gradually burns, the pore connection accelerates, and even the new fracture structure is generated, which forms the crisscross fracture network, resulting in a large increase in the porosity. In short, as the temperature gradually increases from $50^{\circ} \mathrm{C}$ to $300^{\circ} \mathrm{C}$, the pore structure in coal undergoes several processes: water evaporation, thermal expansion of the coal matrix, genera- tion of new cracks, and expansion of the pore networks. Thus, the cumulative thermal damage of coal increases with an increase of the temperature, resulting in a significant increase in the porosity.

\section{Discussion}

4.1. The Relationships between the Temperature and Fractal Dimensions Based on $T_{2}$ Spectrum Distributions. The pore structure of coal has a certain self-similarity, as shown in Figure 6. Based on the experimental nuclear magnetic resonance results and the basic principle of fractal geometry, the fractal model of the coal pore structure is obtained by constructing a capillary curve through the $T_{2}$ spectrum curve of the nuclear magnetic resonance experiment. Then, the fractal dimension of the coal pore structure can be obtained, and the quantitative description of the complexity of the coal pore structure can be realized. Additionally, the variation law of the fractal dimension of the coal structure at different temperatures can be further compared to reveal the mechanism of thermal damage on the pore structure evolution in the coal body [38]. 


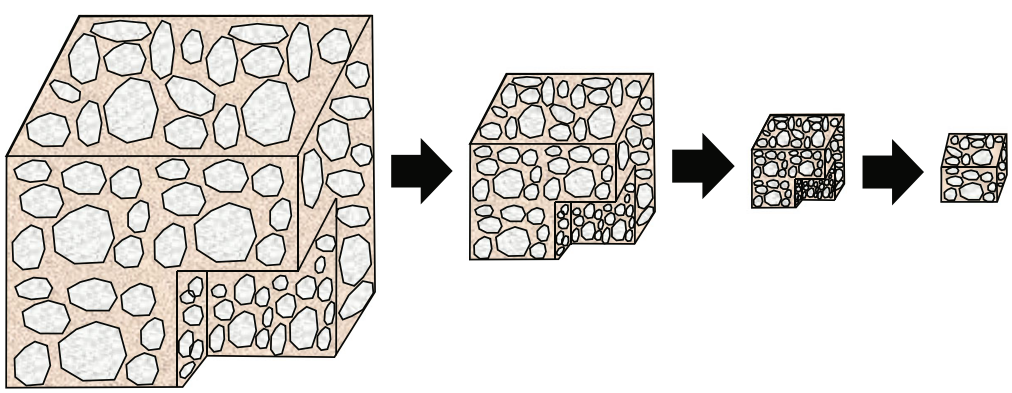

FIGURE 6: The diagrammatic sketch of self-similarity of a coal pore structure (the brown part is the coal matrix, and the gray part is the pore structure).

The algorithm for calculating the fractal dimension of the coal structure based on the $T_{2}$ spectral curve is as follows [39]:

$$
\lg \left(S_{v}\right)=(3-D) \lg \left(T_{2}\right)+(D-3) \lg T_{2 \max },
$$

where $V$ is the pore accumulate volume fraction corresponding to the transverse relaxation time, which is less than $T_{2}$ of the total pore volume, $T_{2}$ is the transverse relaxation time, $T_{2 \max }$ is the maximum transverse relaxation time, $D$ is the measured pore volume fractal dimension, and $S_{v}$ is the cumulative pore volume.

Then, the fractal dimension based on the $T_{2}$ spectrum of NMR can be expressed as:

$$
D=3-k \text {. }
$$

$k$ is the linear slope of fitting $\lg \left(T_{2}\right)$ and $\lg \left(S_{v}\right)$ based on the NMR experiments.

Based on the above equations, first, according to the change points of the relationship curve between $\lg \left(T_{2}\right)$ and $\lg \left(S_{v}\right)$, the demarcation points of the fractal dimension of the pore volume are obtained [40], which are $10.7227 \mathrm{~ms}$, $9.3260 \mathrm{~ms}, 24.7708 \mathrm{~ms}$, and $28.4804 \mathrm{~ms}$; when the values of transverse relaxation time are less than the above values, the fluid in the pores of the corresponding four coal samples is in a bound state. Therefore, the corresponding pore diameters are $0.43 \mu \mathrm{m}, 0.37 \mu \mathrm{m}, 0.99 \mu \mathrm{m}$, and $1.14 \mu \mathrm{m}$, respectively. The boundary points define the structure of adsorption pores and seepage pores. Then, based on the basic principle of fractal theory, $\lambda_{\max } / \lambda_{\min }$ should be greater than $10^{2}$ [40]. Therefore, for the four coal samples taken from $\mathrm{XG}$ and HS, $0.0048 \mu \mathrm{m} / 49.31 \mu \mathrm{m}, \quad 0.0037 \mu \mathrm{m} / 37.30 \mu \mathrm{m}$, $0.0099 \mu \mathrm{m} / 99.08 \mu \mathrm{m}$, and $0.0114 \mu \mathrm{m} / 113.92 \mu \mathrm{m}$ are selected as the minimum/maximum pore diameters, and the corresponding smaller pore fractal dimension, $D_{\mathrm{mNMR}}$, the corresponding larger pore fractal dimension, $D_{\mathrm{MNMR}}$, and the overall pore fractal dimension, $D_{\mathrm{NMR}}$, are obtained, and the calculation results are shown in Table 3.

The fractal dimension can reflect not only the fractal information of the coal body but also the complexity of the pore structure [41]. It can be seen from Table 3 that during the entire heating process, $D_{\mathrm{mNMR}}$ of the XG coal samples are between 2.22 and $2.48, D_{\mathrm{MNMR}}$ of the XG coal samples are between 2.976 and $2.995, D_{\mathrm{mNMR}}$ of the HS coal samples

\begin{tabular}{|c|c|c|c|c|}
\hline \multirow{2}{*}{ Temperature $/{ }^{\circ} \mathrm{C}$} & \multicolumn{4}{|c|}{$D_{\text {mNMR }}$} \\
\hline & XG-1 & XG-2 & HS-1 & HS-2 \\
\hline 50 & 2.4705 & 2.3288 & 2.6248 & 2.6760 \\
\hline 100 & 2.4535 & 2.3264 & 2.5970 & 2.6730 \\
\hline 200 & 2.4472 & 2.2831 & 2.6233 & 2.6684 \\
\hline 300 & 2.4569 & 2.2295 & 2.5560 & 2.5697 \\
\hline \multirow{2}{*}{ Temperature $/{ }^{\circ} \mathrm{C}$} & \multicolumn{4}{|c|}{$D_{\text {MNMR }}$} \\
\hline & XG-1 & XG-2 & HS-1 & HS-2 \\
\hline 50 & 2.9944 & 2.9927 & 2.9844 & 2.9882 \\
\hline 100 & 2.9919 & 2.9916 & 2.9834 & 2.9869 \\
\hline 200 & 2.9913 & 2.9889 & 2.9727 & 2.9742 \\
\hline 300 & 2.9795 & 2.9759 & 2.9138 & 2.9162 \\
\hline \multirow{2}{*}{ Temperature $/{ }^{\circ} \mathrm{C}$} & \multicolumn{4}{|c|}{$D_{\mathrm{NMR}}$} \\
\hline & XG-1 & XG-2 & HS-1 & HS-2 \\
\hline 50 & 2.8627 & 2.8333 & 2.8661 & 2.8866 \\
\hline 100 & 2.8518 & 2.8335 & 2.8636 & 2.8851 \\
\hline 200 & 2.8475 & 2.8277 & 2.8444 & 2.8647 \\
\hline 300 & 2.8482 & 2.8230 & 2.7897 & 2.8013 \\
\hline
\end{tabular}

TABLe 3: The calculation results of $D_{\mathrm{mNMR}}, D_{\mathrm{MNMR}}$, and $D_{\mathrm{NMR}}$.

are between 2.55 and 2.63, and $D_{\mathrm{MNMR}}$ of the HS coal samples are between 2.913 and 2.989, indicating that the smaller pore structure of the four coal samples is less complex, and the larger pore structure is more complex. Among them, the small pore complexity of noncaking coal is lower than that of long-flame coal. The larger pore complexity of noncaking coal is higher than that of long-flame coal. Combined with Figure 4, it can be found that the content and connectivity of microtransitional pores of the noncaking coal are higher than that of the long-flame coal, while the content and connectivity of medium-large pores of the noncaking coal are lower than that of the long-flame coal. At the same time, according to the metamorphic characteristics of two coals $[42,43]$, it can be seen that the noncaking coal is more oxidized than the long-flame coal in the initial stage of the coal formation, and the carbocyclic ring grid structure of the coal matrix is more regular, resulting in the lower complexity of micropore structure. Compared with the noncaking coal, the long-flame coal contains more humic acid during the coal formation and is easy to weather and fragment during the storage. It is easier to form interconnected 

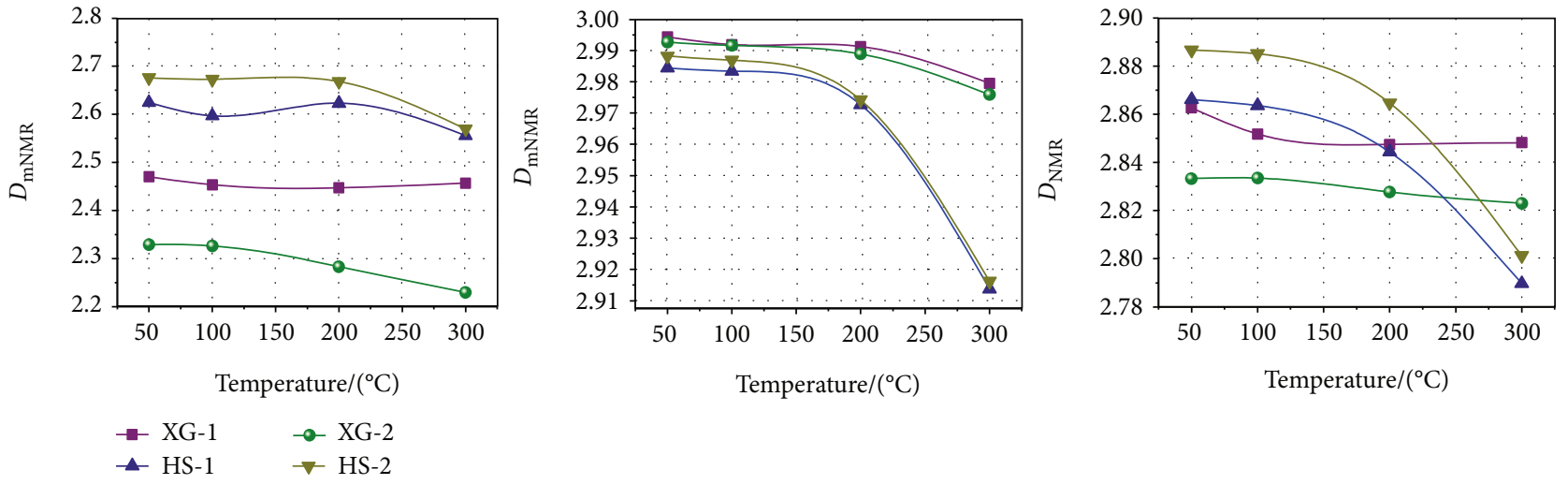

Figure 7: Relationships between the temperature and the fractal dimensions.

pore networks when forming the meso-macropore structure, resulting in the complexity of the meso-macropore structure is lower.

In order to further analyze the relationship between the fractal dimension and the temperature more intuitively, the relationships between $D_{\mathrm{mNMR}}, D_{\mathrm{MNMR}}$, and $D_{\mathrm{NMR}}$ of four coal samples and the temperature are shown in Figure 7.

It can be seen from Figure 7 that, firstly, the temperature has the certain negative correlation with the $D_{\mathrm{mNMR}}, D_{\mathrm{MNMR}}$, and $D_{\mathrm{NMR}}$ of four coal samples, indicating that as the temperature increases, the complexity of the internal pore structure of the coal body is mostly decreasing. The reason is that during the entire heating process, the thermal damage is accumulating, the internal structure of the coal body changes more and more drastically, and the connectivity between the pores is getting better and better, so the complexity of the pore structure is getting lower and lower. Secondly, the $D_{\text {mNMR }}$ of four coal samples change with slightly the temperature, $D_{\mathrm{MNMR}}$ and $D_{\mathrm{NMR}}$ change dramatically with the temperature, and with the increase of temperature, the decreasing range is more and more large, which shows that the decrease of the complexity of large-scale pore structure dominates the decrease of the complexity of pore structure of the whole coal body; that is to say, the complexity of larger pores is more easily affected by the temperature under thermal damage; this is due to the fact that under the condition of thermal damage, the meso-macropores in the low metamorphic coal develop faster, and it is easier to form interconnected pore structure networks. Finally, during the heating process of $200-300^{\circ} \mathrm{C}$, the fractal dimension values of pore structure of four coal samples are greatly reduced. This is because when the temperature is higher than $200^{\circ} \mathrm{C}$, a large number of pyrolysis products in coal escape, which is much larger than the moisture loss at the initial stage of heating up, leading to sudden changes in the coal structure, forming a large number of interconnected pore groups [44], and finally leading to the sudden decreases of the complexity of the pore structure of the coal.

4.2. The Improved Temperature-Permeability Fractal Model. According to the analyses of the above experimental results, in the whole heating process of $50-300^{\circ} \mathrm{C}$, the structure of the low metamorphic coal body has experienced the evaporation of internal moisture and gas, the expansion and deformation of the coal matrix, the gradual connection of pore channels, and the generation of microcracks. These structural changes reflect the changes in the complexity of coal pores and the fractal characteristics and permeability of coal. This has a great influence on the fractal characteristics and permeability characteristics of coal. In this paper, starting from the relationship between the temperature and porosity, taking the fractal dimension as a bridge, the fractal model of temperature-permeability is constructed to quantitatively describe the influence mechanism of temperature on coal permeability characteristics.

$\mathrm{Yu}$ and $\mathrm{Li}$ [45] deduced the fractal dimension of the pore area and tortuosity based on the fractal characteristics of the pore structure in porous media.

$$
D_{f}=2-\frac{\ln \phi}{\ln \left(\lambda_{\min } / \lambda_{\max }\right)} .
$$

$\lambda_{\min }$ is the minimum pore diameter, $\lambda_{\max }$ is the maximum pore diameter, $\phi$ is the porosity, and $D_{f}$ is the theoretical fractal dimension of the pore area; among them, for twodimensional space and three-dimensional space, the fractal dimension $D_{f}$ ranges are $0<D_{f}<2$ and $0<D_{f}<3$, respectively.

$$
D_{T}=1+\frac{\ln \tau_{\mathrm{av}}}{\ln \left(L_{0} / \lambda_{\mathrm{av}}\right)} .
$$

$\tau_{\mathrm{av}}$ is the average tortuosity, $\lambda_{\mathrm{av}}$ is the average capillary diameter, $\lambda_{\mathrm{av}}=D_{f} \lambda_{\max }^{2} /\left(D_{f}-1\right), L_{0}$ is the length of a unit square on which a set of pores or particles distributes whose fractal distribution is assumed to be satisfied, $L_{0}=[((1-\varnothing) / \varnothing)$ $\left.\left(\pi D_{f} \lambda_{\max }^{2} / 4\left(2-D_{f}\right)\right)\right]$, and $D_{T}$ is the fractal dimension of tortuosity; among them, for two-dimensional space and three-dimensional space, the fractal dimension $D_{T}$ ranges are $0<D_{T}<2$ and $0<D_{T}<3$, respectively. 
The fractal permeability model is based on the capillary bundle model [46-48], as shown in formula (7):

$$
K=\frac{\left(\pi D_{f}\right)^{1-D_{T} / 2}\left[4\left(2-D_{f}\right)\right]^{1+D_{T} / 2}}{128\left(3+D_{T}-D_{f}\right)}\left(\frac{\phi}{1-\phi}\right)^{\frac{1+D_{T}}{2}} r_{\max }^{2} .
$$

$r_{\max }$ is the maximum pore radius, $D_{f}$ is the theoretical fractal dimension of pore volume in three-dimensional space, $D_{T}$ is the tortuosity fractal dimension in three-dimensional space, $\phi$ is the porosity, and $K$ is the liquid permeability.

The temperature-permeability fractal model can be obtained by substituting the fitting relationship in Figure 5 and $D_{\text {MNMR }}$ into formula (7), as shown in formula (8).

$$
\begin{aligned}
K= & \frac{\left(\pi D_{\mathrm{MNMR}}\right)^{\left(1-D_{T}\right) / 2}\left[4\left(2-D_{\mathrm{MNMR}}\right)\right]^{\left(1+D_{T}\right) / 2}}{128\left(3+D_{T}-D_{\mathrm{MNMR}}\right)} \\
& \cdot\left(\frac{a T^{2}+b T+C}{1-C-a T^{2}-b T}\right)^{\left(1+D_{T}\right) / 2} r_{\max }^{2} \cdot
\end{aligned}
$$

$r_{\max }$ is the maximum pore radius, $D_{\mathrm{MNMR}}$ is the larger pore fractal dimension, represents the complexity of the seepage pore structure, $D_{T}$ is the tortuosity fractal dimension in three-dimensional space, $T$ is the temperature, $K$ is the liquid permeability, and $a, b$, and $c$ are all constants.

The calculation results of the parameters obtained from formulas (5)-(8) are summarized in Table 4.

The relationships between the permeability measured by formula (7), formula (8), and the NMR fluid experimental temperatures for the four coal samples are shown in Figure 8.

As shown in Figure $8, K_{3}$ is calculated by formula (8). The larger pore part parameter is selected as the effective seepage channel size, including the larger pore fractal dimension $D_{\text {MNMR }}$, while $K_{2}$ is calculated by formula (7), the theoretical fractal dimension of pore volume is used to calculate the permeability, and the calculation result is more ideal. However, the real pore structure inside the coal body is complex and tortuous, and there are dead or closed pores. Therefore, the calculated theoretical permeability is different from the permeability calculated by the improved model, $K_{3}<K_{2}$; meanwhile, $K_{1}$ is the NMR test liquid to measure the permeability, whose target object is the full pore structure parameters of the entire coal body. At the same time, when the temperature is increased to 200 and $300^{\circ} \mathrm{C}$, due to the high temperature, new cracks in the coal body are constantly produced, the pore structure is drastically changed, the connectivity between the pores is greatly enhanced, and the coal body is fragile and unstable, resulting in excessive seepage, so the NMR liquid permeability values of the water injection coal samples are too high, so $K_{1}$ is much larger than $K_{2}$ and $K_{3}$.

To provide a more specific analysis and comparison, the temperature and permeability obtained by the above three methods are fitted separately. The fitting relationships are shown in Table 5.

As shown from Table 5, the permeabilities obtained via the three methods generally all obey the exponential function relationships with the temperature, and there are the positive

\begin{tabular}{|c|c|c|c|c|}
\hline \multirow[t]{2}{*}{ Temperature $/{ }^{\circ} \mathrm{C}$} & \multicolumn{4}{|c|}{$\begin{array}{l}\text { The theoretical fractal dimension of the pore } \\
\text { volume } D_{f}\end{array}$} \\
\hline & $\mathrm{XG}-1$ & $\mathrm{XG}-2$ & HS-1 & HS-2 \\
\hline 50 & 2.0276 & 2.0206 & 2.2192 & 2.1367 \\
\hline 100 & 2.1059 & 2.0473 & 2.2234 & 2.1394 \\
\hline 200 & 2.1452 & 2.1301 & 2.3303 & 2.2777 \\
\hline 300 & 2.2470 & 2.2278 & 2.4940 & 2.4841 \\
\hline \multirow{2}{*}{ Temperature $/{ }^{\circ} \mathrm{C}$} & \multicolumn{4}{|c|}{ The average tortuosity $\tau_{a v}$} \\
\hline & $\mathrm{XG}-1$ & $\mathrm{XG}-2$ & HS-1 & HS-2 \\
\hline 50 & 51.8487 & 46.2035 & 18.5982 & 27.0158 \\
\hline 100 & 35.8153 & 40.8937 & 18.2500 & 26.6839 \\
\hline 200 & 29.1644 & 28.0406 & 11.3033 & 14.2992 \\
\hline 300 & 18.4683 & 18.0048 & 5.5266 & 5.7652 \\
\hline \multirow{2}{*}{ Temperature $/{ }^{\circ} \mathrm{C}$} & \multicolumn{4}{|c|}{ The tortuous fractal dimension $D_{T}$} \\
\hline & XG-1 & $\mathrm{XG}-2$ & HS-1 & HS-2 \\
\hline 50 & 2.5942 & 2.5966 & 2.4746 & 2.5246 \\
\hline 100 & 2.5461 & 2.5802 & 2.4694 & 2.5229 \\
\hline 200 & 2.5185 & 2.5289 & 2.3998 & 2.4344 \\
\hline \multirow[t]{2}{*}{300} & 2.4569 & 2.4667 & 2.2905 & 2.2988 \\
\hline & \multicolumn{4}{|c|}{$\begin{array}{l}\text { The maximum pore radius } r_{\max } \\
\qquad / \mu \mathrm{m}\end{array}$} \\
\hline XG-1 & XG-2 & & & HS-2 \\
\hline 24.66 & 18.65 & & & 56.96 \\
\hline
\end{tabular}
correlations. Upon comparing the trend of the permeability
TABLE 4: Calculation results of $D_{f}, \tau_{\mathrm{av}}, D_{T}$, and $r_{\max }$.

obtained by three methods with the temperature fitting equations, the trend of $K_{3}$ with temperature is closer to that of $K_{1}$ obtained from NMR than that of $K_{2}$. At the same time, based on the above analyses, the $K_{1}$ is too high at high temperature (200-300 $\left.{ }^{\circ} \mathrm{C}\right)$, so the improved temperature-permeability fractal model using formula (8) can better calculate and predict the liquid permeability of the coal body at $200-300^{\circ} \mathrm{C}$ (even at the higher temperature); that is, the temperature, coal body structure parameters, and fractal dimensions are combined to obtain the more accurate liquid permeability of the coal body, and then, the coal permeability characteristics can be further analyzed and discussed.

The change rule of the permeability obtained using three methods is that the permeability increases with an increase of the temperature. In the temperature range of $50-200^{\circ} \mathrm{C}$, water and an organic matter evaporation effect occur in the mesomacropores, and the volume of the meso-macropores continuously increases. However, the thermal expansion of the coal matrix occupies the microtransition pores, resulting in a slower increase in the porosity and less opening of the seepage channels under thermal damage; thus, the increase of the permeability is also slower. In the temperature range of $200-300^{\circ} \mathrm{C}$, the pyrolysis reaction inside the coal body is dramatic. The meso-macropores connect with each other, expand, and even generate new cracks, which lead to the generation of crisscross pores and fracture networks and a continuous increase in the porosity. Additionally, a large number of seepage channels open and ultimately develop 

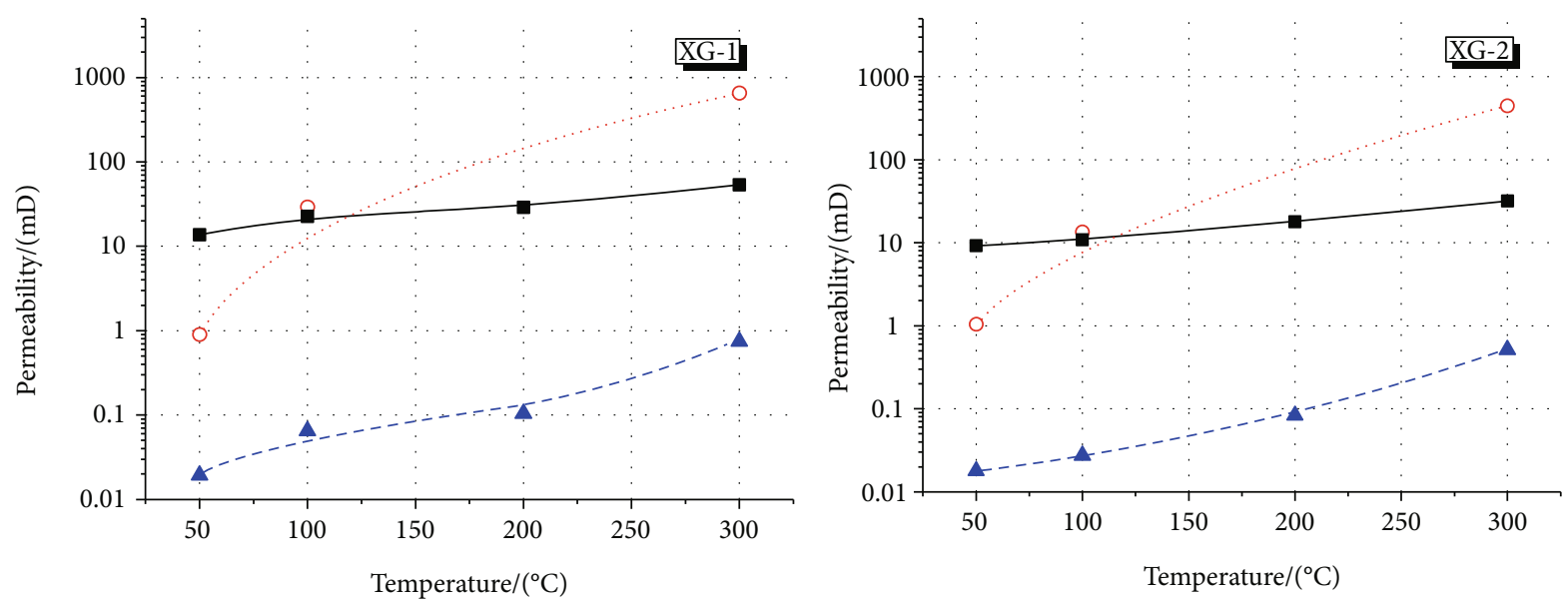

๑. NMR liquid permeability

$\rightarrow$ - Theoretical calculation permeability

- Experimental calculation permeability

(a)
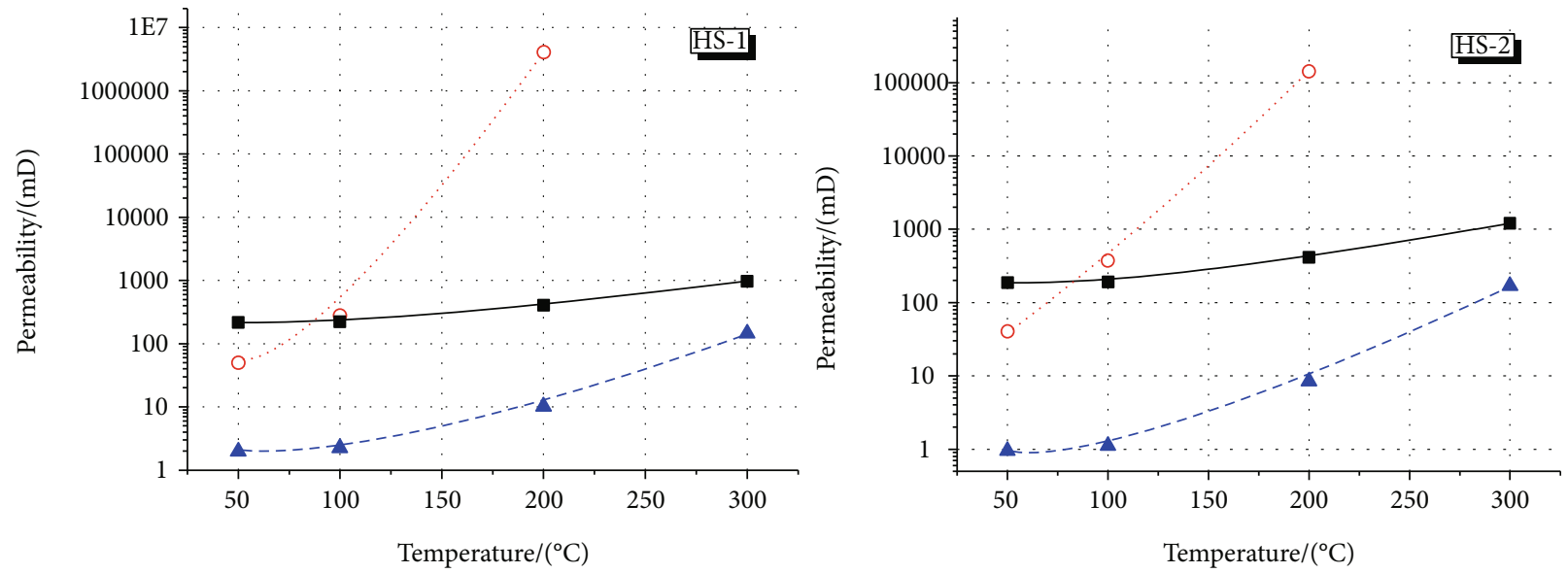

๑. NMR liquid permeability

- Theoretical calculation permeability

- Experimental calculation permeability

(b)

FIGURE 8: Changes in the permeability as measured by the three methods for the coal samples at different temperatures $\left(K_{1}\right.$ is the NMR liquid permeability, $K_{2}$ is the theoretical calculation permeability, and $K_{3}$ is the experimental calculation permeability).

TABLE 5: The fitting results of the temperature and permeability obtained by three methods.

\begin{tabular}{ccccc}
\hline Permeability & \multicolumn{2}{c}{ XG-1 } & & XG-2 \\
& $R^{2}$ & Fitting equation & $R^{2}$ & Fitting equation \\
$K_{1}$ & 0.74 & $y=10^{0.01 \mathrm{x}-0.1}$ & 0.88 & $y=10^{0.01 \mathrm{x}-0.2}$ \\
$K_{2}$ & 0.94 & $y=10^{0.002 \mathrm{x}+1.1}$ & 0.99 & $y=10^{0.002 \mathrm{x}+0.8}$ \\
$K_{3}$ & 0.91 & $y=10^{0.005 \mathrm{x}-1.9}$ & 0.96 & $y=10^{0.005 \mathrm{x}-2.1}$ \\
& & HS-1 & & HS-2 \\
Permeability & $R^{2}$ & Fitting equation & $R^{2}$ & Fitting equation \\
$K_{1}$ & 0.93 & $y=10^{0.03 \mathrm{x}-0.4}$ & 0.99 & $y=10^{0.02 \mathrm{x}+0.3}$ \\
$K_{2}$ & 0.93 & $y=10^{0.003 \mathrm{x}+2.1}$ & 0.93 & $y=10^{0.003 \mathrm{x}+2.0}$ \\
$K_{3}$ & 0.91 & $y=10^{0.008 \mathrm{x}-0.3}$ & 0.93 & $y=10^{0.009 \mathrm{x}-0.7}$ \\
\hline
\end{tabular}

in a direction conducive to improving the permeability of the coal, effectively improving the permeability characteristics of the coal. With the accumulation of thermal damage, the complexity of the pore structure decreases, the porosity increases, the connectivity increases, and the permeability significantly increases. Therefore, compared with $K_{2}$ calculated using formula (7), the trend for $K_{3}$ obtained by formula (8) is closer to the measured value of the NMR fluid with an increase of the temperature, which provides the strong theoretical support for further research on the pore structure evolution and permeability characteristics of coal under thermal damage. It also provides the basic theoretical study on stably controlling the underground gasification process and improving the geothermal exploration and mining technology. 


\section{Conclusions}

(1) In this paper, the innovative nuclear magnetic resonance experiment with a temperature control system is used to analyze the evolution mechanism of the pore structure of coal under thermal damage, and the variation rules of the pore size distribution, the porosity, and the permeability of coal in different heating processes are obtained

(2) The porosity of coal samples increases with an increase of the temperature; the meso-macropore structure is more susceptible to the temperature than the microtransitional pore structure; the lower metamorphic degree, the more susceptible the coal is to the temperature

(3) As the temperature continues to increase, the fractal dimension value calculated based on the fractal theory to characterize the complexity of the coal body pore structure is between 2 and 3 , and the fractal characteristics of the coal body structure have not disappeared with the increase of temperature. It is known that with an increase of the temperature, the complexity of the coal pore structure becomes lower and lower, and the reduction in the larger pore structure complexity dominates the reduction of the pore structure complexity of the whole coal body

(4) Based on the theoretical fractal model of the permeability, a fractal model of temperature-permeability is constructed in this paper. With an increase of the temperature, the change law of permeability calculated using the improved model is consistent with that of the permeability measured by NMR. As shown, thermal damage can increase the connectivity and permeability of the coal body, effectively improving the permeability of the coal body and providing the basic theoretical research for the underground coal gasification and geothermal mining

\section{Data Availability}

Some or all data, models, or code generated or used during the study are available from the corresponding author by request (experimental equipment parameters, laboratory experimental results data, etc.).

\section{Conflicts of Interest}

The authors declare that they have no conflicts of interest.

\section{Acknowledgments}

The authors would like to acknowledge the support of the National Natural Science Foundation of China (grant number 51604168, 51934004); the Key Research and Development Plan of Shandong Province, China (grant number 2019GSF111033); the Major Program of Shandong Province Natural Science Foundation (grant number ZR2018ZA0602); and the Taishan Scholars Project Special Funding (grant number TS20190935).

\section{References}

[1] Q. Wang, Z. Q. Li, X. Y. Wang, and Q. L. Hou, "Geothermal water at a coal mine: from risk to resource," Mine Water and The Environment, vol. 35, no. 3, pp. 294-301, 2016.

[2] L. Xin, Z. T. Wang, G. N. Wang et al., “Technological aspects for underground coal gasification in steeply inclined thin coal seams at Zhongliangshan coal mine in China," Fuel, vol. 191, pp. 486-494, 2015.

[3] W. M. Cheng, W. Nie, G. Zhou, Y. B. Yu, Y. Y. Ma, and J. Xue, "Research and practice on fluctuation water injection technology at low permeability coal seam," Safety Science, vol. 50, no. 4, pp. 851-856, 2012.

[4] A. N. Khadse, "Resources and economic analyses of underground coal gasification in India," Fuel, vol. 142, pp. 121128, 2015.

[5] M. Green, "Recent developments and current position of underground coal gasification," Proceedings of The Institution of Mechanical Engineers Part A-Journal of Power and energy, vol. 232, no. 1, pp. 39-46, 2018.

[6] G. H. Ni, K. Dong, S. Li, and Q. Sun, "Gas desorption characteristics effected by the pulsating hydraulic fracturing in coal," Fuel, vol. 236, pp. 190-200, 2019.

[7] W. Z. Du, G. Wang, Y. Wang, and X. L. Liu, "Thermal degradation of bituminous coal with both model-free and modelfitting methods," Applied Thermal Engineering, vol. 152, pp. 169-174, 2019.

[8] B. Kong, E. Y. Wang, and Z. H. Li, "The effect of high temperature environment on rock properties - an example of electromagnetic radiation characterization," Environmental Science and Pollution Research, vol. 25, no. 29, pp. 29104-29114, 2018.

[9] A. B. Alkhasov, D. A. Alkhasova, A. S. Ramazanov, and M. A. Kasparova, "Technologies for the exploration of highly mineralized geothermal resources," Thermal Engineering, vol. 64, no. 9, pp. 637-643, 2017.

[10] P. Y. Guo, M. C. He, L. G. Zheng, and N. Zhang, "A geothermal recycling system for cooling and heating in deep mines," Applied Thermal Engineering, vol. 116, pp. 833-839, 2017.

[11] T. Schintgen, "Exploration for deep geothermal reservoirs in Luxembourg and the surroundings-perspectives of geothermal energy use," Geothermal Energy, vol. 3, pp. 1-30, 2015.

[12] D. J. Thomas, "Abandoned coal mine geothermal for future wide scale heat networks," Fuel, vol. 189, p. 445, 2017.

[13] M. Wu and J. Wang, "Reassembling fractured sand particles using fracture-region matching algorithm," Powder Technology, vol. 338, pp. 55-66, 2018.

[14] X. B. Zhang and Q. H. Hu, "Development of geothermal resources in China: a review," Journal of Earth Science, vol. 29, no. 2, pp. 452-467, 2018.

[15] T. T. Cai, Z. C. Feng, and D. Zhou, "Multi-scale characteristics of coal structure by X-ray computed tomography (X-ray CT), scanning electron microscope (SEM) and mercury intrusion porosimetry (MIP)," AIP Advances, vol. 8, no. 2, pp. 1-12, 2018.

[16] S. D. Chen, D. Z. Tang, S. Tao, X. Y. Ji, and H. Xu, "Fractal analysis of the dynamic variation in pore-fracture systems under the action of stress using a low-field NMR relaxation method: an experimental study of coals from western Guizhou 
in China," Journal of Petroleum Science and Engineering, vol. 173, pp. 617-629, 2019.

[17] Y. Chen, D. M. Liu, Y. D. Cai, and Q. Gan, "Insights into fractal characteristics of pores in different rank coals by nuclear magnetic resonance (NMR)," Arabian Journal of Geosciences, vol. 11, no. 19, p. 578, 2018.

[18] X. C. Li, Y. L. Kang, and M. Haghighi, "Investigation of pore size distributions of coals with different structures by nuclear magnetic resonance (NMR) and mercury intrusion porosimetry (MIP)," Measurement, vol. 116, pp. 122-128, 2018.

[19] Y. X. Zhao, Y. F. Sun, S. M. Liu, Z. W. Chen, and L. Yuan, "Pore structure characterization of coal by synchrotron radiation nano-CT," Fuel, vol. 215, pp. 102-110, 2018.

[20] Y. X. Zhao, Y. F. Sun, S. M. Liu, K. Wang, and Y. D. Jiang, "Pore structure characterization of coal by NMR cryoporometry," Fuel, vol. 190, pp. 359-369, 2017.

[21] S. D. Zhou, D. M. Liu, Y. D. Cai, Y. B. Yao, and Z. T. Li, “3D characterization and quantitative evaluation of pore-fracture networks of two Chinese coals using FIB-SEM tomography," International Journal of Coal Geology, vol. 174, pp. 41-54, 2017.

[22] Z. T. Li, D. M. Liu, Y. D. Cai, Y. B. Yao, and H. Wang, "Pore structure and compressibility of coal matrix with elevated temperatures by mercury intrusion porosimetry," Energy, Exploration \& Exploitation, vol. 33, no. 6, pp. 809-826, 2015.

[23] H. W. Liu, B. Jiang, J. G. Liu, and Y. Song, “The evolutionary characteristics and mechanisms of coal chemical structure in micro deformed domains under sub-high temperatures and high pressures," Fuel, vol. 222, pp. 258-268, 2018.

[24] F. Wang, L. Jiao, P. Lian, and J. Zeng, "Apparent gas permeability, intrinsic permeability and liquid permeability of fractal porous media: carbonate rock study with experiments and mathematical modelling," Journal of Petroleum ence and Engineering, vol. 173, 2018.

[25] Y. D. Cai, D. M. Liu, Z. J. Pan, Y. B. Yao, J. Q. Li, and Y. K. Qiu, "Pore structure of selected Chinese coals with heating and pressurization treatments. Science China," Earth Science, vol. 57, no. 7, pp. 1567-1582, 2014.

[26] H. Natalia, "Temperature induced development of porous structure of bituminous coal chars at high pressure," Journal of Sustainable Mining, vol. 15, no. 3, pp. 120-124, 2016.

[27] K. Jolanta, "Oxidatively and thermally altered high-volatile bituminous coals in high-temperature coal fire zone No. 8 of the Wuda Coalfield (North China)," International Journal of Coal Geology, vol. 176, pp. 8-35, 2017.

[28] H. Wu, Y. F. Zhou, Y. B. Yao, and K. J. Wu, "Imaged based fractal characterization of micro-fracture structure in coal," Fuel, vol. 239, pp. 53-62, 2019.

[29] Z. Liu, H. Yang, W. Y. Wang, W. M. Cheng, and L. Xin, "Experimental study on the pore structure fractals and seepage characteristics of a coal sample around a borehole in coal seam water infusion," Transport in Porous Media, vol. 125, no. 2, pp. 289-309, 2018.

[30] J. F. Zhu, J. Z. Liu, Y. M. Yang, J. Cheng, J. H. Zhou, and K. F. Cen, "Fractal characteristics of pore structures in 13 coal specimens: relationship among fractal dimension, pore structure parameter, and slurry ability of coal," Fuel Processing Technology, vol. 149, pp. 256-267, 2016.

[31] X. H. Shi, J. N. Pan, Q. L. Hou et al., "Micrometer-scale fractures in coal related to coal rank based on micro-CT scanning and fractal theory," Fuel, vol. 212, pp. 162-172, 2018.
[32] C. Peng, C. C. Zou, Y. Q. Yang, G. H. Zhang, and W. W. Wang, "Fractal analysis of high rank coal from southeast Qinshui basin by using gas adsorption and mercury porosimetry," Journal of Petroleum Science and Engineering, vol. 156, pp. 235249, 2017.

[33] S. Davies and K. J. Packer, "Pore size distributions from nuclear magnetic resonance spin-lattice relaxation measurements of fluid-saturated porous solids," I. Theory and simulation Journal of Applied Physics, vol. 67, no. 6, pp. 3163-3170, 1990.

[34] S. Q. Wang, Y. G. Tang, H. Chen, P. H. Liu, and Y. M. Sha, "Chemical structural transformations of different coal components at the similar coal rank by HRTEM in situ heating," Fuel, vol. 218, pp. 140-147, 2018.

[35] L. Z. Xiao, NMR Imaging Logging Principles and Applications (in Chinese), Science Press, Beijing, 1998.

[36] B. B. Huoduote, Coal and gas outburst, S. Z. Song and Y. A. Wang, Eds., China Industry Press, Beijing, 1966.

[37] A. H. Thompson, A. J. Katz, and C. E. Krohn, "The microgeometry and transport properties of sedimentary rock," Advances in Physics, vol. 36, no. 5, pp. 625-694, 1987.

[38] G. Q. Zhang, G. J. Hirasaki, and W. V. House, "Internal field gradients in porous media," Petrophysics, vol. 44, no. 6, pp. 422-434, 2003

[39] C. M. Zhang, Z. B. Chen, Z. S. Zhang, J. Li, H. S. Ling, and B. D. Sun, "Fractal structure of reservoir rock pores based on $\mathrm{T}_{2}$ spectrum distribution of NMR," Journal of Oil and Gas Technology (JJPI), vol. 29, no. 4, pp. 80-86, 2007.

[40] Y. T. Zhang, D. M. Wang, and X. X. Zhong, "Features of fissure sharp in coal borehole and variation law with temperature," Coal Science and Technology, vol. 35, no. 11, pp. 73-76, 2007.

[41] B. M. Yu, P. Xu, M. Q. Zou, J. C. Cai, and Q. Zheng, Fractal porous media transport physics, Science Press, Beijing, 2014.

[42] H. Liu, J. Mou, and Y. Cheng, "Impact of pore structure on gas adsorption and diffusion dynamics for long-flame coal," Journal of Natural Gas ence \& Engineering, vol. 22, pp. 203-213, 2015.

[43] K. Seshagiri Rao, P. P. S. Sarma, D. P. Agrawal, and R. Vaidyeswaran, "Studies on the storage of high volatile non-caking coal: pretreatment with light tar," Indian Journal of Technology, vol. 6, pp. 368-371, 1968.

[44] X. M. An, F. S. Wang, and X. W. Dong, "Analysis of pore structure characteristics of coal samples at different temperatures," Journal of Hebei United University (Natural Science Edition), vol. 37, no. 4, pp. 65-68, 2015.

[45] B. M. Yu and J. H. Li, "Some fractal characters of porous media," Fractals, vol. 9, no. 3, pp. 365-372, 2011.

[46] R. B. Bird, W. E. Stewart, and E. N. Lightfoot, Transport Phenomena, Wiley, New York, 1990.

[47] F. Wang, K. Yang, and J. Cai, "Fractal characterization of tight oil reservoir pore structure using nuclear magnetic resonance and mercury intrusion porosimetry," Fractals, vol. 26, no. 2, article 1840017, 2018.

[48] P. Xu and B. Y. Yu, "Developing a new form of permeability and Kozeny-Carman constant for homogeneous porous media by means of fractal geometry," Advances in water resources, vol. 31, no. 1, pp. 74-81, 2008. 